\title{
Crise e industrialização no Brasil entre 1929 e 1954: a reconstrução do Estado Nacional e a política nacional de desenvolvimento
}

\author{
WILSON CANO*
}

RESUMO: O texto analisa os principais efeitos decorrentes da política econômica de defesa do café e do extraordinário esforço de industrialização desencadeado pelo Estado Nacional entre 1929 e 1954. Distingue o desenvolvimentismo do I e II governo Vargas (30-45 e 5154), contrapondo-o à frustrada tentativa de retorno liberal de Dutra (46-50). Destaca o importante esforço de reconstrução do Estado e da introdução de instrumentos de controle da política econômica nacional, materializados pelo extraordinário trabalho da Assessoria Econômica da Presidência (51-54), criada por Vargas, onde pontificaram nomes de grandes brasileiros como Rômulo de Almeida, Ignácio Angel, Jesus Soares Pereira, Cleanto Paiva Leite e Tomás P. Acioli Borges, verdadeiros artífices de nossos principais projetos e planos de desenvolvimento de então.

PALAVRAS-CHAVE: Brasil industrialização 1929-1954; reforma do Estado; política econômica; desenvolvimentismo.

ABSTRACT: Crisis and industrialization in Brazil between 1929 and 1954. This paper focuses on the main effects brought about by the economic policy of coffee crisis and industrialization efforts led by the National State. It distinguishes Vargas' developmentalism mandates I and II (30-45 and 51-54), comparing it to Dutra's unsuccessful attempt to restore liberalism (46-50). It highlights the important reconstruction effort of the state and the introduction of national control instruments of economic policy, embodied the extraordinary work of the Vargas' Presidency Economic Advisory (51-54), where great Brazilian names were enshrined, such as Rômulo de Almeida, Ignácio Rangel, Jesus Soares Pereira, Cleanto Paiva Leite and Tomás P. Acioli Borges, true builders of the major projects and development plans at that time.

KEYWORDS: Brazil industrialization 1929-1954; reconstruction of the State; developmentalism; economic policy; Vargas advisory.

JEL Classification: N66; O25. 
Utilizo, nesta introdução, hipótese que usei em outro texto sobre o processo de industrialização na América Latina, que se dá entre 1929 e 1979, a qual sofreu forte inflexão a partir daí1. Restrinjo a análise, neste texto, ao período 1929-1954.

A hipótese também significa, infelizmente, que após 1979 "os tempos seriam outros", com muito menos brechas, menos coragem e menos vontade política para um enfrentamento internacional responsável e cooperativo. Ou seja, após 1979, os EUA, secundados pelos demais imperialismos, retomaram as ações mediante as quais nos impuseram o chamado "Consenso de Washington", centrado pela dominação da finança internacional. Isso reduziu fortemente nossa soberania nacional e nos impôs - com a aceitação de nossas elites — uma verdadeira ressurreição liberal-conservadora, nossa velha conhecida, hoje vestida de "nova" roupagem, a da (falsa) "ida ao primeiro mundo".

Por várias circunstâncias históricas, quisemos e pudemos explorar mais corajosa e inteligentemente a soberania nacional resultante de brechas e contradições internas e externas que ocorrem nesse período: a Grande Depressão entre 1929 e 1937; a Revolução de 1930; a influência e nosso envolvimento na II Guerra Mundial; o surgimento de uma bipolaridade, com a expansão da ex-URSS; a vitória da Revolução de Mao em 1949, a Guerra da Coreia (1951-53); o esforço dos EUA para reconstruir o Japão e a Alemanha; e a Guerra Fria.

Mas é bom lembrar que a excepcionalidade do período não significa que estávamos trilhando o almejado caminho do desenvolvimento econômico, que nos pudesse levar, algum dia, a atingir o mesmo padrão de vida dos países desenvolvidos. Furtado já havia esclarecido esta questão desde 1974, em seu clássico O mito do desenvolvimento. Tentávamos desde os anos 1930, isto sim, alterar nosso padrão de crescimento via industrialização, como sabiamente teorizou a Cepal, ao final da década de 1940, e melhorar o nível de vida da nação.

\section{O PERÍODO 1929-1950}

Para o Brasil, o período 1929-1945 representa a ruptura com um passado político liberal e com uma política econômica livre-cambista. Foram principalmente duas radicais mudanças: uma profunda reorganização do Estado Nacional, que passaria a ser fortemente intervencionista, e uma radical mudança do processo de acumulação de capital, que alterou a mudança do Centro Dinâmico da Economia Nacional, como disse Furtado, agora comandado pelo investimento autônomo².

\footnotetext{
* Professor Titular do Instituto de Economia da Unicamp. E-mail: wcano@unicamp.br. Este texto foi apresentado no evento comemorativo "100 anos de nascimento: o pensamento vivo e o legado de Ignácio Rangel e Rômulo de Almeida”, na Mesa Contextualização do período da Assessoria Econômicopolítica de Vargas (1951-1954): a modernização do Estado e o projeto de desenvolvimento brasileiro. Organização do BNDES, 26-6-2014. Submetido: 28/junho/2014; Aprovado: 17/setembro/2014.

${ }^{1} \mathrm{O}$ texto está em Cano (1999, cap. 1).

${ }^{2}$ Cf. o clássico de Furtado (1961, caps. 30-32).
} 
A "Crise de 1929" atingiu duramente a América Latina e sua economia primário exportadora, e com mais intensidade, os países mineiros e Cuba, então dominada, de fato, pelos EUA. A maioria dos demais países sofreu fortes pressões, principalmente dos EUA e da Inglaterra, com a imposição de "acordos" draconianos e elevações tarifárias sobre nossas exportações. A todos atingiu a forte redução da capacidade de importar, a exaustão das reservas e o drástico constrangimento das finanças públicas, o que impediu, de fato, a continuidade de condução de uma política econômica liberal.

Contudo, a reação e enfrentamento à crise não foi uniforme ${ }^{3}$. Venezuela, Equador e América Central mantiveram-se, durante alguns anos, mergulhados na crise, aguardando a "volta aos dias de glória" do liberalismo. O Brasil, Argentina, México e Chile constituíram o grupo de países que tomaram atitudes de enfrentamento mais rápidas, com a substituição de governos liberais, via processos revolucionários ou eletivos, e implantando ousadas alterações na política econômica e na forma de intervenção econômica do Estado Nacional.

O Brasil foi um precursor nessa tarefa. Ela nos exigiu não só uma rápida e efetiva política estatal de defesa da renda e do emprego, mas também a construção de uma política de industrialização, única rota para sair da grave crise e ingressar em formas econômicas urbanas mais modernas e progressistas ${ }^{4}$. Exigiu, acima de tudo, uma firme vontade política e a ousadia de utilizar o que tínhamos de soberania nacional.

Para tanto, tivemos que construir um novo estado e redesenhar o painel da política econômica com os instrumentos necessários para aquela tarefa, entre os quais a moratória da dívida externa, sempre que necessária, o controle (e a desvalorização) do câmbio, uma nova política de comércio exterior, de crédito, de juros e tributária, além da organização de normas para reger os contratos e o mercado de trabalho e uma mais avançada legislação política, social e trabalhista ${ }^{5}$.

A (re)construção do Estado exigiu também a reformulação ou a criação de inúmeros órgãos:

- uns, de caráter mais geral, como o Conselho Técnico de Economia e Finanças (CTEF), o importante Conselho Federal de Comércio Exterior (CFCE), o famoso DASP (Departamento Administrativo do Serviço Público), o Conselho Nacional de Política Industrial e Comercial, a Comissão de Planejamento Econômico (esta, não aprovada no Legislativo), a Superintendência da Moeda e do Crédito em 1945 e o BNDE em 1952;

- vários outros, de caráter mais específico, como a Carteira de Crédito Agrícola e Industrial do Banco do Brasil (CREAI); a Comissão de Financiamento da Produção, vários Departamentos, Comissões ou Conselhos de âmbito

\footnotetext{
${ }^{3}$ Ver a respeito SEERS (1962).

${ }^{4}$ Sobre a política de defesa ver Cano (2002).

${ }^{5}$ Sobre os temas do Estado e da política econômica, embora exista ampla bibliografia, restrinjo-me a algumas das principais: Baer, Kerstenetzky e Villlela (1973), Diniz (1978), Draibe (1985) e Lessa (1975).
} 
setorial (café, açúcar e álcool, sal, pinho, mate, cacau, petróleo, minerais, etc.). Estes últimos, de grande importância econômica, passaram, de órgãos de âmbito político e econômico regional, para o âmbito político nacional. Além disso, o Estado teve ainda que formar equipes técnicas para dar conta desse empreendimento vultoso. Teve que formar uma burocracia que administrasse o planejamento e a execução dos principais projetos de desenvolvimento.

Mas a mudança de orientação da política econômica - e que se mantém durante esses 15 anos, só se tornou possível por uma série de fatos, além dos arrolados mais acima. Em primeiro lugar, há que ressaltar que, embora tivéssemos transitado para uma economia capitalista, as condições para o funcionamento desse embrionário capitalismo estavam concentradas no estado de São Paulo. Essa trajetória paulista já é marcante desde a segunda década do século XX: entre 1911-13 e 1919, enquanto a indústria de transformação crescia à taxa média anual de 4,4\% no Brasil, em São Paulo ela havia sido de 7,5\%. Entre 1920 e 1928, essas taxas respectivas foram $4,4 \%$ e $6,6 \%{ }^{6}$.

Em São Paulo, as transformações ensejadas por esse nascente capitalismo já mostravam que, ao final dos anos 1920, a hegemonia da economia cafeeira já não era plena, seja pelo pesado ônus que causava ao estado - financiamento para expansão do plantio e de estoques - , seja porque outros compartimentos da economia haviam crescido tanto quanto ou mais do que o café, e portanto suas massas econômicas (de produção e/ou de circulação) situavam-se em níveis muito próximos ao da massa da cafeicultura. Assim ocorreu com a indústria de transformação - que inclusive havia gerado grande capacidade produtiva ociosa -, e diversificado sua estrutura produtiva, com a inclusão de novos segmentos, notadamente da metalúrgica e da química. Essa expansão ampliou o mercado interno para seus produtos e para a agricultura mercantil produtora de alimentos e matérias-primas (exclusive café), expandindo a urbanização e os principais segmentos de serviços.

Quebrar a espinha dorsal da cafeicultura - a mãe de todos os males econômicos e políticos do país, segundo os tenentes - significaria na verdade quebrar o nascente capitalismo, porque: essa cafeicultura estava endividada com os bancos públicos e privados, e se quebrasse, arrastaria consigo o nascente sistema financeiro nacional; se quebrasse, causaria imenso desemprego e queda da renda, ceifando os mercados internos da indústria e da outra agricultura mercantil; com isso, também soçobrariam setores como os do comércio e dos transportes. Acresça-se que a arrecadação dos impostos de importação (federal) e de exportações (estadual), violentamente constrangidos, levariam de roldão as finanças públicas de todo o país.

O café estava moribundo, mas não morto. A crise não teria saída senão pelo amparo da renda e do emprego, isto é, do mercado interno. Mas as maiores resistências políticas fatalmente estariam concentradas no café e em seus aliados liberais mais próximos, o comércio e provavelmente os bancos. Assim, quebrar a espinha

${ }^{6}$ Conforme Cano (2007, p. 79). 
do café deixou de significar sua morte, passando a ser a maior extração possível de seu excedente, via câmbio, transferindo-o aos novos setores dinâmicos, principalmente à indústria. Foi a compensação que se fez à custa, fundamentalmente, do aumento do gasto público, com o financiamento e destruição de estoques invendáveis de café. E tudo isso se fez, com uma carga tributária nacional pequena, que saltou de cerca de $12 \%$ do PIB na década de 1920, para apenas $15 \%$ na de 1940 . Ao mesmo tempo, a política econômica passou a ter seu eixo principal no câmbio, garantindo um barateado abastecimento interno de máquinas e matérias-primas industriais. A crescente demanda de crédito pela indústria também passou a ter canais prioritários de atendimento.

Isto não quer dizer que pelo menos parte dos interesses dos capitais mercantis agrário e urbano não fossem atendidos. Mas ainda assim permaneceram à espreita, aguardando o momento para exigir a volta ao passado: o câmbio livre e o Estado não intervencionista. A propósito disto, convêm não esquecer que as novas frações burguesas do capital — indústria, agricultura mercantil e finanças —, a despeito de que adquiriram "corpo capitalista moderno", mantinham entretanto, em grande medida, sua "alma mercantil"".

Entre 1930 e 1945, com o I Vargas, pudemos avançar a industrialização, graças à inequívoca condução de uma política nacional de desenvolvimento. Entendamos, contudo, que tal política continha muitas falhas temáticas e sociais, e não poderia conter, para saná-las, maiores recursos e uma estrutura específica de planejamento. A política anticíclica aplicada na economia cafeeira gerou o efeito renda que permitiu a manutenção da demanda interna em elevado nível, estimulando a indústria a produzir, substituindo as importações para as quais não contávamos com divisas. Isto estimulou o processo de industrialização, que forçou a integração do mercado nacional. Mas também o restante do Brasil recebeu fortes impactos positivos desse processo, pois, se entre 1928 e 1939 a indústria de transformação cresceu em São Paulo, à taxa média anual de 7,3\%, a do restante do Brasil foi de $6,4 \%$ e, entre 1939 e 1949 , elas foram, respectivamente, $9.8 \%$ e $7,8 \%$.

No início, o processo de industrialização foi mais facilitado pela existência de grande capacidade ociosa industrial. Depois, à medida que essa capacidade se esgotava, e que a implantação de novas plantas em novos segmentos exerciam altas pressões sobre as importações, os problemas também cresceram. Não só os de caráter financeiro e cambial, mas também os de caráter da administração pública, do planejamento e da inflação.

O menor interesse do capital estrangeiro e a debilidade do capital nacional obrigaram o Estado a assumir também uma função produtora, notadamente em setores considerados prioritários, com a implantação de várias empresas estatais no período, entre as quais: a Companhia Siderúrgica Nacional (CSN), a Companhia

\footnotetext{
${ }^{7}$ Sobre essas metamorfoses "incompletas" do capital mercantil em países subdesenvolvidos, notadamente no Brasil, ver Cano (2010).

${ }^{8}$ Conforme Cano (2007, p. 79).
} 
Vale do Rio Doce (CVRD), a Companhia Nacional de Álcalis (CNA) e a Companhia Hidroelétrica do São Francisco (CHESF). Em 1943, por questões da guerra e de segurança nacional, foi implantada a Fábrica Nacional de Motores (FNM), para reparação e construção de motores de avião, depois convertida em fábrica de caminhões adequados às estradas brasileiras de então. No período o Estado encampou e nacionalizou as empresas de navegação e, logo após a guerra, encamparia e nacionalizaria o restante do sistema ferroviário9. Mas esse estado não produziu apenas mercadorias e serviços, pois também produziu vários empresários nacionais.

Entre 1946 e 1950, com Dutra, sofremos a ameaça de um retorno ao liberalismo econômico, a qual, contudo, em face do nosso velho, conhecido e recorrente problema cambial só resistiu por pouco tempo. A ideia de retomada da liberdade cambial não poderia resistir a um exame responsável da realidade de nossas reservas internacionais, as quais, embora altas ao final da guerra, eram em sua maior parte constituídas de moedas inconversíveis, e, por isso, tínhamos situação fortemente deficitária em dólares.

Em junho de 1947 retomávamos ao controle cambial e impúnhamos o licenciamento prévio de importações. O sistema de controle cambial perduraria, e, paradoxalmente, conviveríamos, entre 1938 e 1952, com uma taxa oficial de CR \$ $18,72 /$ US $\$$, mas durante a guerra a inflação foi superior a $200 \%$ e, durante o governo Dutra, acumulou outros $60 \%$. Certamente, parte do problema da valorização cambial se deveu ao temor sobre a inflação. Mas o regime de licenciamento proporcionou, para o Estado, via ágios sobre a taxa oficial, recursos que serviram para amenizar as dificuldades das finanças públicas, contidas pela impossibilidade política de se fazer uma reforma tributária progressiva. Para a indústria, continuou a proporcionar importações de bens de produção barateados, subsidiados por conta de grande parte das exportações.

Mesmo assim, os contratempos não tiveram o fôlego suficiente para conter o muito que avançáramos, e não conseguiram nos afastar do caminho acelerado da industrialização, cuja taxa média anual de crescimento entre 1946 e 1950, para o Brasil, teria sido em torno de $10 \%{ }^{10}$. Foi compreensível, ao fim da guerra, a extinção da Comissão de Mobilização Econômica (CME), órgão que entretanto foi muito eficiente e oportuno para a elaboração de vários projetos estratégicos. Outros órgãos também tiveram seu fim, como o DNC, o CNPIC e o importante CFCE; o DASP foi reestruturado, diminuindo sua amplitude de ação. Mas outros, embora de menor expressão econômica, também foram criados, como a Comissão Executiva de Defesa da Borracha e a Fundação da Casa Popular.

$\mathrm{Na}$ verdade, o regime, agora formalmente democratizado, não poderia retroceder ao liberalismo pré-1930, por várias razões: (i) os interesses industriais haviam

\footnotetext{
${ }^{9}$ Cf. Bawer, Kerstenetzky e Villela (1973, pp. 890-892).

${ }^{10}$ Esta taxa deve ser tomada com cautela, dada a precariedade do aparelho informativo então existente e da complexidade da formação de preços industriais naqueles anos. Para uma discussão desses indicadores, ver Malan e outros (1977), especialmente o Apêndice V.
} 
crescido e se diversificado, e as complexidades de ordem técnica e financeira aumentaram sobremodo, exigindo maior atenção do Estado; (ii) embora as exportações continuassem a sofrer o confisco cambial, o Estado amparava em seu sistema de crédito oficial o setor agroexportador; (iii) a urbanização e a classe trabalhadora urbana tiveram crescimento acelerado, impondo novas e maiores ações públicas de caráter urbano e social; (iv) o crescimento e a maior complexidade da economia exigiam constante ampliação da infraestrutura.

Uma tentativa apenas formal de organizar parte de tais demandas, foi a confecção do Plano SALTE (saúde, alimentação e transporte), instrumento que, na verdade, mais se prestaria a organizar o destino e a apropriação parlamentar de verbas do que propriamente atingir determinadas metas de ação.

\section{O PERÍODO 1951-1954}

O retorno de Vargas (1951-1954) teve mais clareza em seus propósitos nacionalistas e industrializantes. A despeito do período em grande parte conflituoso com as forças reacionárias do país, avançamos ainda mais na consolidação da implantação da indústria leve e do início da marcha rumo à indústria pesada. Cerceado pela direita, Vargas se suicida em 1954, e seu gesto, tendo tido forte impacto político sobre as massas populares, certamente conseguiu adiar (para 1964) o golpe tão almejado pela direita.

\section{O contexto político e internacional}

$\mathrm{Na}$ área da economia e do desenvolvimento econômico, os países subdesenvolvidos assistiam a uma série de fatos importantes para uma maior tomada de consciência da necessidade de continuar avançando na industrialização. De um lado, a enorme cooperação técnica, econômica, financeira e política dos EUA para a reconstrução europeia e japonesa, e a ausência de qualquer apoio similar para a América Latina. De outro, crescera fortemente, desde o final da guerra, a discussão teórica, acadêmica e política sobre a temática do desenvolvimento econômico e social, e seus desdobramentos urbano e regional.

A ONU também se preocupou com essa situação e criou Comissões Econômicas Regionais para estudar os problemas econômicos de várias partes do globo e propor políticas para seus desenvolvimentos. Em 1947 foram criadas as da Europa e da Ásia-Pacífico; em 1948, a da América Latina e Caribe (CEPAL); em 1958 a da África e em 1973 a da Ásia Ocidental. A criação da Cepal não foi vista com bons olhos pelos EUA e os governos da Argentina e Brasil tiveram que fazer gestões especiais para sua aprovação.

Acrescente-se a Revolução da China em 1949, alargando o mundo socialista e a Guerra da Coreia (1951-1953), que fez com que os EUA dessem decisivo apoio (“desenvolvimento a convite”) à Coreia. Este foi o início dos "30 anos gloriosos" 
do capitalismo, com a Europa Ocidental e o Japão assimilando gradativamente o padrão tecnológico dos EUA e o chamado American way of life.

A eleição de Eisenhower (Partido Republicano) em 1953 aumentaria as tensões dos EUA contra governos latino-americanos, em especial os desenvolvimentistas e progressistas, como eram Vargas e Perón. Animosidades, desconfianças e atitudes negativas entre os EUA e vários governos latino-americanos cresceram ainda mais com o aquecimento da Guerra Fria. Esse clima contaminou as relações nacionais internas, tanto as do Executivo com o Congresso e Setor Privado quanto algumas realizadas dentro do próprio Executivo, entre autoridades e técnicos.

Vargas tinha consciência das muitas dificuldades que teria em seu mandato de governo. Sua larga experiência sobre as principais transformações ocorridas no Brasil e no mundo certamente lhe deram a certeza de que seu governo teria que enfrentar novos e mais complexos problemas econômicos, ao mesmo tempo que sua área de manobra política seria muito difícil. A UDN, criada em 1945, era o partido mais claramente de direita, liberal e inteiramente a favor do capital estrangeiro, era o maior e mais hostil inimigo de Vargas e conquistou $27 \%$ das cadeiras da Câmara nas eleições de 1950, enquanto o PSD, partido mais próximo ao setor agrário exportador, conquistou $37 \%$ delas.

Contudo, sua base de apoio na classe trabalhadora continuaria imprescindível, mas insuficiente. Assim, sua notável engenhosidade política teria que enfrentar o difícil jogo de conflito de interesses entre os principais setores da economia: o setor agrário e exportador e o industrial, e governar com um precário apoio parcial do PSD. Quanto aos militares, a corrente nacionalista o apoiava, mas a corrente à direita e mais favorável ao capital estrangeiro crescera muito depois de 1945, e notadamente durante o governo Dutra.

\section{O contexto da economia nacional}

O processo de industrialização, embora ainda muito restringido, havia dado passos importantes. A participação setorial do PIB teve importante alteração: a indústria de transformação subira de $14,5 \%$ para $19,3 \%$. A estrutura produtiva deste segmento também se alterou, com a diminuição do peso dos bens de consumo não durável, de $67,5 \%$ para $60,7 \%$, praticamente consolidando a implantação dos segmentos leves.

A participação dos bens intermediários subiu de $25,9 \%$ para $31,7 \%$ e o agregado de bens de consumo durável e de capital, ainda muito incipiente, de 4,7\% para $6,7 \%$, mostrando o quanto é difícil a implantação deste segmento numa economia subdesenvolvida. Já havíamos implantado a siderurgia, mas os ramos industriais mais complexos de bens de produção (metal-mecânica, química, material de transporte e elétrico), haviam dado apenas seus primeiros passos. Este, justamente, era um dos pontos cruciais de seu programa de industrialização. Outro, não menos importante, era o da infraestrutura necessária a dar suporte à industrialização, notadamente transporte e energia.

Mas esses setores, como regra geral, tinham tecnologias e processos que pra- 
ticamente impunham grandes escalas para suas plantas, que, mesmo para o Brasil, significavam uma operação à escala nacional. Em muitos casos a escala era maior do que o mercado interno, causando capacidade ociosa e custos de produção mais altos. Além disso, as maiores escalas exigiam elevados investimentos, e, em muitos casos, proporcionavam retorno de prazo maior. Este ponto é duplamente importante, pois afugentava o capital privado nacional, ao mesmo tempo em que o IDE para esses setores ainda não se tornara atrativo.

Esses investimentos traziam, em seus processos produtivos, tecnologias up-to-date, que demandavam licenças de fabricação, uso de patentes e pagamentos de royalties. Mas suas empresas líderes, todas oligopolizadas, exigiam difíceis negociações.

Haviam sido poucos os projetos de grande porte implantados no período 1930-1950, como a CSN, e que tinham maiores efeitos para a frente do que para trás. Mas parte de suas demandas preexistiam, e eram atendidas por importações. Mas os novos setores industriais criariam os dois tipos de efeitos, exigindo portanto estudos mais acurados do que hoje se chamam cadeias produtivas ou mesmo complexos industriais. Isto envolve problemas novos, e exigem um processo analítico e decisório de planejamento, muito mais acurado, que leve em conta também as demandas derivadas desses projetos, pincipalmente em termos de câmbio e de financiamento.

$\mathrm{O}$ acelerado aumento da produção e o elevado montante de novos investimentos, embora substituíssem importações, geravam, paradoxalmente, uma demanda derivada ainda maior de importações de máquinas e componentes, o que exigiria um planejamento específico da oferta e demanda de divisas ${ }^{11}$.

Mas essa acelerada dinâmica do investimento pressionaria as débeis finanças públicas. Estas, pressionadas desde 1929, não haviam passado por nenhuma reforma profunda, principalmente porque elites e proprietários se recusavam a aceitar uma tributação sobre a propriedade, notadamente a da terra! Sobre a renda, o sistema também fora contido, sendo sua carga reduzida. Mas também o sistema financeiro, até então basicamente constituído pelos bancos comerciais, era inadequado e insuficiente para dar conta dessa expansão. Ambas questões padeciam de um equacionamento maior.

Ao mesmo tempo, a maior complexidade técnica desses projetos exigia níveis maiores de conhecimento técnico e de qualificação de mão de obra, de seus trabalhadores, técnicos, gerentes, empresários e, principalmente, dos planejadores. E este fato obviamente, de alguma forma, teria que ser inserido na Agenda de Planejamento, ou seja, o da formação de quadros para o desenvolvimento.

Durante todo esse processo, o Estado teve não apenas que cumprir com as tarefas acima assinaladas, mas também com a de criar empresários nacionais, pois isso era matéria escassa, pelo menos para os setores modernos que se pretendia implantar. Mais ainda, dada a debilidade do capital nacional e o pouco interesse do capital estrangeiro em nosso desenvolvimento, o Estado teve que assumir também a função primordial de produtor de bens e serviços fundamentais a esse processo: energia, transportes, comunicações, educação, siderurgia, petróleo, mineração, etc.

${ }^{11}$ Esse efeito contraditório do processo de substituição de importações foi apontado por Tavares (1972). 


\section{Reformas e política econômica}

Mas o Estado, a despeito de entre 1930 e 1950 ter feito várias reformas e reestruturações, não estava aparelhado para dar conta, principalmente, desses problemas acima mencionados. Era imprescindível, portanto, novas e profundas reformulações de sua Administração e Planejamento.

Em fins de 1950 Dutra negociara com os EUA uma cooperação técnica para diagnosticar e elaborar projetos de infraestrutura e indústria de base no Brasil. $\mathrm{O}$ entendimento, aprovado por Vargas após sua eleição, resultou na Comissão Mista Brasil-EUA, criada em 1951 e encerrada já em 1953, dada a mudança na política externa daquele país. A CMBEU elaborou 41 projetos nas áreas de transporte, energia e indústria de base, e entre suas sugestões havia a da criação de um Banco para repassar os recursos externos pleiteados junto aos EUA (recursos do Eximbank e do BIRD) e administrar recursos internos para o financiamento restante daqueles projetos. A sugestão se concretizou em 1952, com a criação do Banco Nacional de Desenvolvimento Econômico - BNDE. Contudo, dos US\$ 387 milhões pleiteados, só foram concedidos US\$ 181 milhões.

Em 10/1952, a Cepal e o BNDE firmaram Acordo de Colaboração, instituindo o Grupo Misto de Estudos Cepal-BNDE, que aprofundaria os estudos da CMBEU, alguns dos quais seriam executados durante o II Vargas, e que, mais tarde, fariam parte do famoso Programa de Metas do futuro governo JK (1956-1960).

Concordo com Sonia Draibe, que afirma que o II Vargas tinha, de fato, um programa informal de desenvolvimento capitalista, centrado na industrialização e na infraestrutura. Resumidamente, abarcava os seguintes grandes objetivos:

- na agricultura, projetos de armazenagem, modernização, comercialização e de colonização (este praticado mais no Centro Oeste, retomando sua anterior "Marcha para o Oeste");

- na infraestrutura e indústria de base: energia elétrica, transportes (com prioridade para o ferroviário), comunicações, exploração e refino de petróleo, química e componentes para um futuro parque automotivo;

- na urbanização, em temas como o dos salários, previdência, assistência médica, abastecimento e controle de preços;

- uma política de regulamentação do capital estrangeiro;

- o âmbito regional também foi pensado, com a criação do Banco do Nordeste (1952) e da Superintendência do Plano de Valorização Econômica da Amazônia (1953).

Esse governo chegou a ensaiar uma profunda reforma administrativa, com acentuada centralização do planejamento, mas esses projetos (o da Reforma Administrativa e o da criação do Conselho Nacional de Planejamento) foram rejeitados pelo Congresso. Dentre os órgãos criados para levar adiante seus objetivos, destaque-se:

- a Comissão Nacional de Política Agrária (1951), junto ao Ministério da Agricultura, sob a qual foram criados o Instituto Nacional de Colonização 
(INIC), o Banco Nacional de Crédito Cooperativo (BNCC) e a Cia. Nacional de Seguros Agrícolas;

- a Comissão de Desenvolvimento Industrial-CDI (1951), subordinada ao Ministério da Fazenda, para tratar dos projetos industriais e que vai imprimir um sistema novo de análise e administração de projetos, criando Grupos Executivos para o setor automotivo (GEIMA) e o de material elétrico pesado. Cabe lembrar que estas instituições constituiriam a espinha dorsal do Programa de Metas, com o Conselho de Desenvolvimento (no lugar da CDI) e seus diversos Grupos Executivos;

- a Comissão de Coordenação e Desenvolvimento dos Transportes (1952);

- a Comissão Nacional para o Bem Estar e a Comissão Federal de Abastecimento e Preços (COFAP), em 1951;

- a Comissão de Aperfeiçoamento de Pessoal Especializado de Nível Superior-CAPES, (1951);

- a Comissão de Revisão Tarifária (1954), que faria o estudo das tarifas aduaneiras, da qual surgiriam os projetos sobre a Reforma Aduaneira e da criação do Conselho de Política Aduaneira, só aprovados em 8/1957;

Para as duas áreas mais emblemáticas - energia elétrica e petróleo - onde seria impossível a participação do capital privado nacional e onde eram grandes os conflitos com o capital estrangeiro, a solução foi a criação de duas empresas estatais, a Petrobras (1953) e a Eletrobras (em 1954, mas só autorizada pelo Congresso em1961).

Os principais objetivos da política de desenvolvimento econômico estavam consubstanciados no Programa de Reaparelhamento Econômico, elaborado em 1951, para cujo financiamento foi criado o Fundo de Reaparelhamento Econômico, aprovado em 1953, que seria constituído por: um adicional restituível sobre o Imposto de Renda, de 15\%; por 3\% das receitas anuais da Previdência Social; por até $4 \%$ dos depósitos das Caixas Econômicas Federais; e por $25 \%$ das reservas técnicas anuais das Companhias de Seguro e Capitalização. O BNDE seria o administrador desse Fundo e de outros recursos públicos, e seu papel seria fundamental na articulação e coordenação desses investimentos, junto com a CDI.

Caberia à Sumoc, a partir de 1953, construir o Orçamento de Câmbio e a priorização de importações, além de aumentar o controle estatal sobre a moeda e o crédito, alargado via Tesouro Nacional e Carteira de Redescontos do Banco do Brasil.

A carga tributária nacional era pequena, embora tivesse subido cerca de $15 \%$ na década de 1940 , e atingiria cerca de $18 \%$ na de 1960 . O imposto de importação, que na Reforma de 1934 representava cerca de $40 \%$ da Receita Fiscal federal, foi perdendo sua importância, ante a inflação e ao congelamento da taxa cambial, passando, em 1956, a representar apenas 3\%. Por isso, um sistema livre de importações nos levaria ao desastre cambial, pois o grau de proteção que esse imposto 
proporcionava, em 1934, era em torno de $35 \%$, ao passo que em 1956 caíra para apenas $5 \%{ }^{12}$.

O governo elaborou proposta para uma profunda reforma tributária, que, como é sabido, não foi aprovada. Da estreiteza dessa capacidade fiscal e da debilidade de nosso balanço de pagamentos resultariam maiores pressões inflacionárias ao final do período. A reforma aduaneira só seria aprovada em 1957.

Embora conhecendo esse risco, Vargas deliberadamente flexibilizou o controle das importações durante o biênio 1951-1952, período da Guerra da Coreia, por temer que a guerra se prolongasse e isto causasse graves problemas de abastecimento externo de matérias-primas e bens de capital, paralisando ou dificultando muito o prosseguimento da industrialização ${ }^{13}$.

A despeito da melhoria dos preços de exportações — notadamente do café as importações em 1951 e 1952 aumentaram $83 \%$ em relação a 1950, causando, em 1952, enorme déficit (US\$ 300 milhões, ou cerca de $21 \%$ das exportações desse ano). Por sua vez, os pesados déficits em Serviços e Rendas em 1951 e 1952 implicaram déficits em transações correntes que somaram US\$1,2 bilhão nesse biênio, causando déficit acumulado, em atrasados comerciais no biênio 1952-1953, de US\$ 600 milhões. Essa situação, insustentável a partir de meados de 1952, deflagrou grave crise cambial, obrigando o governo a efetuar nova reforma cambial, em janeiro-fevereiro de 1953.

A reforma de 2/1953 (Lei 1807 e Instrução 48 da Sumoc) consistiu em criar um mercado livre (taxa oficial mais sobretaxa), além do oficial. Neste, ficaram as importações essenciais e as exportações de café, cacau e algodão. No livre, os gastos financeiros (remessa de lucros - máximo de 10\% —, de capital, de juros máximo de $8 \%$ - e turismo) e pagamentos parciais de exportações que o governo queria estimular. Estas foram classificadas em três categorias, sendo permitida, no mercado livre, a venda de somente $15 \%$ do valor exportado, para a primeira, $30 \%$ para a segunda e $50 \%$ para a terceira.

Contudo, o esquema foi insuficiente para debelar a crise, e em outubro foi substituído por um sistema de taxas múltiplas de câmbio (Lei 2145 e Instrução 70 da Sumoc), que vigorou até agosto de 1957. Foi reinstituído, junto ao Banco do Brasil, o monopólio de compra de divisas das exportações, que passaram a receber, além da taxa oficial, CR \$ 5/dólar as do café e CR \$10/dólar as demais.

As remessas de lucros e de juros permaneceram no mercado oficial, mas com uma sobretaxa determinada pela Sumoc, assim como as importações mais essenciais (petróleo e derivados, papel de imprensa, trigo e bens de capital priorizados). As demais importações foram classificadas em cinco categorias, segundo sua essencialidade, com as respectivas divisas obtidas em leilões, os quais foram importantes geradores de receita fiscal extra para o governo.

O encarecimento das importações restringiu-as, com o valor (em US\$) do biê-

\footnotetext{
${ }^{12}$ Dados do imposto de importação estimados por Gomes da Silva (2009).

${ }^{13}$ Além dos problemas decorrentes da guerra, houve também problemas na oferta de trigo da Argentina, elevando os gastos com essas importações, e queda internacional dos preços do algodão, diminuindo as receitas de exportações.
} 
nio 1953-1954 caindo 26,5\% em relação ao de 1951-1952. Isto, mais os atrasados comerciais e financeiros de 1953 (cerca de US\$ 600 milhões, equivalente a 50\% das importações) e alguns (raros) empréstimos permitiram o desafogo momentâneo do balanço de pagamentos.

Mesmo com o forte aumento do PIB e da produção industrial, a receita fiscal do governo federal se manteve, entre 1947 e 1955 em torno de 7,5\% do PIB, em que pesem os novos e pesados encargos públicos assumidos no período ${ }^{14}$. Certamente os leilões e ágios cambiais apropriados pelo governo ajudaram a impedir um desequilíbrio maior nas contas públicas. Com efeito, do déficit de 1,5\% (do PIB) do último ano de Dutra, Vargas obteve superávits de 0,6\% no biênio 1951-1952 e déficits de $0,5 \%$ no de 1953-1954. Não foi daí, evidentemente, que surgiram as pressões inflacionárias. A elevação dos preços das exportações, o aumento dos custos de câmbio e dos preços industriais aceleraram a alta dos preços, fazendo com que o Índice Geral de Preços acumulasse, entre 1950 e 1954, cerca de 80\%, elevando por isso as pressões da classe trabalhadora, que obteve, em 1954, reajuste de $100 \%$ do salário mínimo.

Entre 1950 e 1955, a participação da agropecuária no PIB manteve-se em torno de $25 \%$, sua taxa média anual de crescimento foi de $4,4 \%$ e a permanência de seu peso certamente se deve ao aumento real de seus preços. No mesmo período, o setor industrial ultrapassa a agropecuária, passando de $25 \%$ para $27 \%$ e a indústria de transformação, de $19 \%$ para $21 \%$, tendo crescido à taxa média anual de $7,4 \%$.

Não há como fazer a análise da mudança estrutural da indústria de transformação nesse período, uma vez que os dados para o período 1950-1955 são incompletos em termos dos ramos produtivos, só existindo para os anos dos censos de 1949 e 1959. Nesse período - fortemente influenciado pelos grandes investimentos do Programa de Metas - a estrutura mostra importantes mudanças: a participação dos bens de consumo não durável cai de $60,7 \%$ para $45,2 \%$; a de bens intermediários sobe de $31,7 \%$ para $38 \%$ e de bens de consumo durável e de capital, de $6,7 \%$ para $13,2 \%{ }^{15}$. Contudo, os dados existentes para 1950-1954 mostram claramente que os ramos que menos cresceram foram, em média, os produtores de bens de consumo não durável e, enquanto a média da indústria cresceu $50 \%$, a química, metalúrgica, minerais não metálicos e borracha cresceram em torno de $80 \%$, mostrando claramente a tendência do período.

Em que pese a ousadia do Estado - em especial a de enfrentar e superar conflitos de interesses com o capital estrangeiro e com vários segmentos do capital privado nacional - notadamente, mas não exclusivamente com o agroexportador -, fez -se a transição para o Brasil urbano e industrial. Mas a possibilidade de que as eleições de 1955 pudessem ser ganhas por um candidato que comungasse com o projeto industrial e nacionalista de Vargas, acirrou os ânimos da direita, que precipitou a crise de agosto de 1954 . O suicídio conseguiu a proeza de não só evitar o golpe direitista que pretendia obstar o projeto nacional de Vargas, mas tam-

\footnotetext{
${ }^{14}$ E manter-se-ia em torno dessa média, até a reforma tributária de 1967.

${ }^{15}$ Cf. Cano (2007, p. 97).
} 
bém permitir o prosseguimento da industrialização, e, ainda, adiar por 10 anos o golpe da direita.

\section{A Assessoria Econômica da Presidência da República (AERP)}

Vargas conhecia bem o perigoso terreno que precisava trilhar e, para isso, tentou criar vários anteparos. À animosidade do capital estrangeiro — principalmente dos EUA -, concordara antes de eleito com o pedido de Dutra aos EUA, para a vinda de uma missão técnica, efetivamente constituída em 1951. Na formação de seu Ministério, aceitou composições com o partido majoritário (PSD), convidando conhecidas figuras que destoavam de seus progressistas objetivos. Tais composições atingiram áreas de grande complexidade política e econômica, como os Ministérios da Fazenda, da Agricultura e das Relações Exteriores. Mas, ao mesmo tempo, se beneficiava de apoio de alguns governadores que haviam participado ou apoiado seu governo anterior. No caso do petróleo, teve a seu favor a campanha "O Petróleo é nosso", desencadeada pela ala nacionalista do Clube Militar, que foi para as ruas e converteu-se numa grande campanha nacional.

A dimensão da obra, a complexidade técnica e administrativa para elaborar e pôr em marcha vários projetos de longo alcance, e as dificuldades políticas envolvidas, certamente foram as questões fundamentais que nortearam sua ideia para criar um organismo especial que fosse de sua total confiança e que, além da capacidade técnica requerida, pudesse também evitar, mediar ou ajudar a mediar conflitos políticos que fatalmente adviriam. Esse órgão, criado logo após a posse, em janeiro, foi a Assessoria Econômica da Presidência da República.

A AEPR, além de executar suas atribuições formais — assessoria ao Presidente, elaboração de estudos e projetos e atribuições de planejamento - , precisaria cumprir com uma mediação técnica, legislativa e política para, inclusive, e citando palavras de Cleanto P. Leite, "escapar ao cerco político ao qual ele (Vargas) tinha sido obrigado na escolha de seus ministros" ${ }^{16}$. Essa mediação também se faria junto a alguns membros do Legislativo, ou usando "táticas legislativas", e na própria CMBEU. Daí que seus principais membros teriam que ser verdadeiros estrategistas e deveriam ter uma estreita comunhão com as proposições de Vargas e seu ideário industrialista e, principalmente, nacionalista.

A AEPR era composta por vários técnicos - alguns em caráter permanente $\mathrm{e}$ outros como eventuais -, alguns lotados no Gabinete da Presidência e outros vinculados a vários órgãos públicos (como o DASP) ou à FGV, e chefiada por Rômulo de Almeida ${ }^{17}$. Contudo, entre seus membros havia fortes divergências políticas e ideológicas quanto à intervenção do Estado, participação do capital estran-

\footnotetext{
${ }^{16}$ Cf. entrevista concedida ao CPDOC em 1988, apud Lima (2009 B, p. 217).

${ }^{17}$ Sobre o tema específico da AERP, ver o excelente conjunto de entrevistas concedidas por Rômulo, em Almeida (1986). Ver ainda Lima (2009 B) e Cabral (2009), dos quais extraí algumas das referências que faço sobre essa instituição.
} 
geiro e da própria industrialização imaginada por Vargas ${ }^{18}$. Rômulo soube selecionar um grupo restrito de técnicos, aprovados por GV, sobre os quais não deviam pairar dúvidas quanto à fidelidade e discrição aos projetos do governo. Vargas concentrou, neles seu relacionamento com a AEPR, sendo que no caso dos projetos de maior dimensão política - como os do petróleo e energia, apenas esse grupo restrito tinha acesso a eles.

Além de outros membros da AEPR, esse restrito grupo era constituído por Cleanto Paiva Leite, Ignácio Rangel, Jesus Soares Pereira e Tomás Pompeu Acióli Borges: todos nordestinos, de esquerda e nacionalistas, e três deles haviam lutado contra Vargas no Estado Novo. Não cabe neste texto fazer a biografia desses notáveis brasileiros, mas tão somente citar alguma referência sobre os seus desempenhos.

Rômulo, por seu passado e experiência, bem como por seu trabalho de assessoria junto a Euvaldo Lodi e Roberto Simonsen, na CNI, assumiu a Chefia da AEPR até 1953, quando sai para assumir a presidência do BNB, tinha maior presença no contato com empresários e políticos, e conhecia os problemas industriais e de desenvolvimento. Soares Pereira — que em 1953 assume a chefia da AEPR —, por sua formação e estudo da questão energética foi o principal formulador dos Planos de Eletrificação e do Petróleo (e dos projetos de criação da Petrobras e da Eletrobras), no que foi ajudado por Rangel, mais voltado para a industrialização, reforma agrária e a problemática do desenvolvimento na economia brasileira. Este, por sua experiência, viria a ser o coordenador do Plano de Metas. Cleanto, por sua formação, dedicou-se mais aos difíceis e fundamentais planos de reforma administrativa, a projetos legislativos e a questões sociais. Tomás Pompeu era especialista em agricultura e reforma agrária, além de grande conhecedor do Nordeste.

Todos eles conheciam economia, os trabalhos pioneiros da Cepal e as principais discussões internacionais sobre o Desenvolvimento Econômico, que haviam surgido no imediato pós-guerra, e participavam do debate nacional então existente. Conheciam também, e na prática do cotidiano, as técnicas sobre a economia do projetamento, o que muito lhes ajudou nessas tarefas.

Como já referido, cabia à CMBEU a formulação de vários projetos, notadamente industriais e de infraestrutura, e à CDI (que fazia parte do Ministério da Fazenda) coordenar sua execução. Como a AEPR tinha representações junto a esses órgãos, isso lhe possibilitava intervir não só na elaboração desses projetos, mas na sua reformulação, condução, priorização e execução. Por sua participação direta e indireta, pôde inclusive indicar vários técnicos para exercer importantes funções, principalmente nos Grupos Setoriais da CDI.

Para se ter uma ideia da importância e abrangência das atividades da AEPR, resumo abaixo as principais áreas em que ela teve papel decisivo na elaboração e conclusão desses projetos:

- na agropecuária: realizou estudos, propostas e projetos de lei para crédito

\footnotetext{
${ }^{18}$ Por exemplo, Glycon de Paiva e Mario da Silva Pinto (que também faziam parte da CMBEU), situavam-se francamente à direita, contra o nacionalismo, a intervenção do Estado e a favor do capital estrangeiro.
} 
rural, seguro agrícola, preços mínimos, projetos de colonização, criação da CNPA-Comissão de Nacional de Política Agrária, da Carteira de Colonização do Banco do Brasil e do Banco Nacional de Crédito Cooperativo (BNCC);

- na educação e formação de quadros técnicos: projeto de criação da Comissão de Aperfeiçoamento de Pessoal Especializado de Nível Superior-CAPES;

- na industrialização: estudos e projetos para avanço de segmentos da indústria do petróleo (refino e transporte), mineração, indústria química, indústria automotiva, material ferroviário, material elétrico pesado;

- na infraestrutura: os projetos de petróleo (extração, refino e transporte) e de eletricidade, incluindo o carvão e biomassa, além de participar das discussões do projeto de energia nuclear. No de eletrificação, usou a tática de fracionar o problema junto ao Legislativo, dividindo-o em quatro projetos: criação de um imposto federal único sobre energia (derivados de petróleo e eletricidade); criação de um Fundo Federal de Eletrificação, Plano Nacional de Eletrificação (só aprovado em algumas de suas partes) e criação da Eletrobras (só aprovada em 1961);

- na questão regional: participação na elaboração do Plano de Valorização da Amazônia e na criação da SPVEA. Em especial para o Nordeste: reforma agrária, uso social da água, crédito rural, infraestrutura e criação do Banco do Nordeste do Brasil (BNB).

Nos entendimentos com o final do governo Dutra sobre o papel da futura CMBEU, certamente Vargas informou a necessidade que o país tinha de melhorar e expandir sua infraestrutura e de avançar na indústria pesada. A Rômulo, em fevereiro de 1951, lhe transmitiu isso e deu-lhe ainda outras informações sobre aspectos mais críticos de seu programa, incumbindo-lhe a difícil e delicada missão de coordenar a elaboração do documento Mensagem ao Congresso Nacional, de 1951, que deveria ser entregue em março ao Legislativo. Em entrevista, anos mais tarde, Rômulo revelaria as dificuldades para cumprir a missão - inclusive porque a Mensagem era um documento sem precedentes, e precisou ser elaborada em menos de trinta dias. O que Rômulo confessa ter apreendido naquele instante foi a dimensão, em sua totalidade, do programa de Vargas: (que consistia) em uma politica trabalhista, na emancipação econômica e progresso da nação, no desenvolvimento do mercado interno, na indústria de base, na infraestrutura - notadamente energia -, e na melhoria das condições de vida do povo. Claro que o texto deveria ocultar, na medida do possível, o caráter nacionalista de seu projeto, e o elevado grau de intervenção do Estado requerida para tanto ${ }^{19}$.

O trabalho desses homens foi, sem sombra de dúvida, admirável. Mais ainda, suas condutas pessoais para com a Nação e para o Estado, como autênticos servidores públicos, foram exemplares. A obra de "remodelação" do Estado Nacional dando-lhe a necessária sobrevida na administração e no planejamento públicos, a necessária interação Estado-Empresário, a ideia permanente sobre a defesa dos

\footnotetext{
${ }^{19}$ Ver seu depoimento sobre isso, em Almeida (1986, pp. 55-56).
} 
interesses nacionais, a construção de estudos e projetos que transcenderam aquele momento e se estenderam ao futuro, são algumas das lições que nos deixaram. $\mathrm{O}$ país, sem dúvida, muito deve a eles.

A História sempre nos pode ser útil, não para reproduzi-la, mas para repensar suas lições. Não esqueçamos que em 1929 éramos uma economia primário-exportadora, também tínhamos elites conservadoras e nosso Estado tinha uma estrutura não adequada para um projeto de industrialização. A crise superou muito disso, com a Revolução de 1930, com a reestruturação do Estado e uma corajosa política nacional de desenvolvimento.

É preciso hoje, e com urgência, repensar a questão nacional. Não, repito, como uma simples volta ao passado, mas com novos caminhos possíveis para dar continuidade a nosso processo histórico de transformação progressista da economia e da sociedade nacionais. E, repetindo Furtado, preservar e incentivar a cultura e a criatividade nacionais, tão necessárias a essa tarefa. Mas, para isso, será fundamental, de novo, a reconstrução do Estado Nacional.

Concluindo, me permito ainda dizer que "o II Governo Vargas encilhou o cavalo e JK montou-o", ainda que com diferenças importantes.

\section{REFERÊCIAS BIBLIOGRÁFICAS}

Almeida, R. (1986): Voltado para o Futuro. Entrevistas concedidas à Associação dos Sociólogos do Estado da Bahia. BNB, Fortaleza.

Baer, W., Kerstenetzky, I. e Villela, A. V. (1973) As Modificações do Papel do Estado na Economia Brasileira. IPEA, Pesquisa e Planejamento Econômico, v. 3 n. 4.

Cabral, R. (2013) Ideologia, técnica e política em Rômulo Almeida, Jesus Soares Pereira, Cleanto Paiva Leite e Ignácio Rangel, e, Lima (2013a).

Cano, W. (1999) Soberania e Política Econômica na América Latina, UNESP, São Paulo.

Cano, W. (2002) Crise de 1929, Soberania na Política Econômica e Industrialização 2002. In: Cano, W. Ensaios sobre a formação econômica regional do Brasil, ED. Unicamp.

Cano, W. (2007) Desequilíbrios regionais e concentração industrial no Brasil. UNESP, $3^{a}$.ed. São Paulo.

Cano, W. (1979) Reflexões sobre o o Papel do Capital Mercantil na Questão Regional e Urbana do Brasil. Revista da Sociedade Brasileira de Economia Política, no. 27.

Diniz, E. (1978) Empresário, estado e capitalismo no Brasil, 1930-45, Rio de Janeiro, Paz e Terra.

Draibe, S. (1985) Rumos e Metamorfoses: Estado e industrialização no Brasil (1930/1960), Paz e Terra, Rio de Janeiro.

Furtado, C. (1985) Formação Econômica no Brasil. 4a. ed. Rio de Janeiro, Fundo de Cultura.

Gomes da Silva, G. (1961) “A Reforma Aduaneira no Brasil”. (Data imprecisa do original). UNAFISCO, Rev. Tributação em Revista, n. 54, Brasília, 2009

Lessa, C. (1975) Quinze anos de política econômica. Campinas, Univ. Estadual de Campinas, 1975. (Cadernos do Inst. Fil. Ciências Humanas).

Lima, M. C. (Org) (2013 A ) Os Boêmios Cívicos: A Assessoria econômico-política de Vargas (1951-1954). Pensamento Crítico, Centro Internacional Celso Furtado, RJ.

Lima, M. C. (2013 B) “A Assessoria Econômica do segundo governo Vargas e a construção do Estado brasileiro moderno”, In: Lima (2013 A).

Malan, P. S., Bonelli, R., Abreu, M. P. e Pereira, J. E. C. (1977) Política Econômica Externa e Industrialização no Brasil (1939-52). IPEA, RJ.

Seers, D. (1962) "Inflación y crecimiento: Resumen de la experiencia en América Latina". Cepal, Boletín Económico de América Latina, v.VII, n.1, Santiago, 2/1962.

Tavares, M. C. (1972) “Auge e Declínio do Processo de Substituição de Importações no Brasil”. In: Tavares, M. C., Da Substituição de Importações ao Capitalismo Financeiro. Zahar, RJ. 